\title{
A Review on Polyelectrolytes (PES) and Polyelectrolyte Complexes (PECs)
}

\author{
Yubaraj Ghimire \\ Department of Chemistry, Mahendra Morang Adarsh \\ Multiple Campus, Tribhuvan University \\ Biratnagar, Nepal
}

\author{
Ajaya Bhattarai* \\ Department of Chemistry, Mahendra Morang Adarsh \\ Multiple Campus, Tribhuvan University \\ Biratnagar, Nepal
}

\begin{abstract}
Polyelectrolytes are polymers of oppositely charged ions and their properties differ profoundly than their repeating units. Over recent years, much advancement has been made in the synthesis, characterization and application of polyelectrolytes and polyelectrolyte complexes (PECs). There are two kinds of PECs structure: ladder-like structure and scrambled egg model. There are number of elements that influence the synthesis and stability of PEC. Polyelectrolyte complexes are classified based on the type of macromolecules and bonds involved in complexation. It has many applications as flocculation agents, dispersant agents and super-plasticizers. This present article focuses mainly on the polyelectrolytes and polyelectrolyte complexes, their preparation and uses.
\end{abstract}

Keywords-Polyelectrolytes; polyelectrolyte complexes; polymers; flocculation agents; dispersant agents; superplasticizers

\section{POLYELECTROLYTES}

Polymer compounds which bear total positive or negative charge at $\mathrm{pH} 7$ are known as polyelectrolytes. Those numerous substances which have ionic group bearing positive or negative charge on their surfaces has taken into account as polyelectrolytes. Some naturally available polysaccharides obtained from vegetables such as acacia, tragacanth, alginic acid and pectin have the carboxylic groups on them, which get ionized in $\mathrm{pH}$ greater than or equal to 7. A copolymer of acrylic acid known as carbomer is present in artificially prepared carboxylated polymer [1]. The positive or negative charges on the monomer units of the PE are compensated by oppositely charged smaller counter ions which tries to maintain electrical neutrality in the solution. Small negatively charged ions get accompanied by the positively charged polyelectrolyte present in the solution. Similarly, small positively charged particles can be joined with negatively charged PE [2]. If there occurs the little separation of ionic groups of PEs then there may be some extraordinary changes in their characteristics, however, PEs acts like ordinary macromolecules in an uncharged state. Because of incomplete or complete separation of ionic groups, the electrostatic force of attraction can emerge and could prompt changes of polymer properties. If any new charged group is introduced, then characteristics of polyelectrolytes, for example, viscosity, solubility, $\mathrm{pH}$, the dissociation constant, ionic strength, diffusion coefficient, among others, can be changed [3]. The ionic strength of the solution significantly impacts the PE characteristics. At lower ionic strength, due to repulsive interactions between the molecules, in solution, polyelectrolytes slant toward an extended form. But PE will become thicker if the ionic concentration of the solution increases. Because of this uncommon nature, polyelectrolytes have critical significance in different pharmaceutical and biomedical applications, because that there can be various degrees of sizes, viscosity, stability, or morphology for polyelectrolyte complex (PEC) dispersions [4]. Some common examples of polyelectrolytes are poly (acrylic acid) (PAA) and poly(methacrylic acid) (PMA) and their salts, sodium polystyrene sulfonate, DNA, RNA, and other polyacids and polybases. If the polymer has both negative and positive groups after the disintegration of charged groups on the polymer's backbone, then these polyelectrolytes are [5] called polyampholytes. Some examples of this polymer include denatured proteins (e.g., gelatin), proteins in their natural condition, for example, bovine serum albumin or histone proteins, and synthetic copolymers made of monomers with acidic and basic groups. Relying on the $\mathrm{pH}$ of the solution, these PEs may be anionic, cationic, or neutral in the solutions.

Charged polymeric systems drew the researcher's interest because of their important role in the various areas, extending from materials science and colloids to biophysics [6]. The molecular weight and charge density are two important properties of PEs, which are quite different properties from the molecular structure of the polyelectrolytes. They have the ability for application in numerous businesses relying on the degree of electrical charge, distributions of charge and range of molecular weights [7]. The development in the study of these polymeric frameworks has led to the utilization of polyelectrolytes as rheology modifiers, adsorbents, coatings, biomedical implants, flocculants for wastewater treatment, colloidal stabilizers, and suspending agents for medicine delivery systems. Truth be told, the settling properties of polyampholytes were perceived by Faraday over 150 years prior, where the solution of gold colloidal particles was stabilized by gelatin (a polypeptide protein). Toward the start of the twentieth century, this property of gelatin was effectively executed by the photographic business to balance out silver bromide sols [8-10]. Furthermore, the factor by which DNA interacts with histones and responsible for bundling DNA with chromosomes is the presence of the charged groups on the DNA molecule $[11,12]$.

\section{CLASSIFICATION OF PES}

PEs are a type of polymer bearing dissociated ionic groups and are a fascinating class of macromolecule. These molecules exhibit interesting phenomena owing to their dual character of macromolecular chain plus high charge. PEs can be classified in various ways [13]. Based on origin, they are 
classified as natural, synthetic and chemically modified natural polyelectrolytes. For example, proteins are natural PE, poly(styrene sulfonic acid) is synthetic and xanthan gum is chemically modified natural PE. Based on charge (electrochemistry), PEs are divided as polycations(polybase), polyanions(polyacid) and polyampholytes. PEs are grouped into strong and weak polyelectrolytes based on charge density. Strong polyelectrolyte gains spontaneously full charge, while weak polyelectrolyte is only partially charged on dissociation. For example, poly (vinyl sulfate) is strong PE and poly(ethyleneimine) is weak PE.

Depending upon their shape, they are classified into spherical and rigid rod polyelectrolytes. Globular proteins are the examples of spherical polyelectrolyte and poly(p-phenylene) is a rigid rod-shaped polyelectrolyte. Based on the position of ionic sites (i.e. architecture), they are classified as linear, branched and crosslinked polyelectrolyte. For linear polyelectrolyte, if ions are present in the backbone of the polymer then it is known as integral and is called pendant if ions are present in the inside-chain of the polymers. The different known branched structures are comb-like, stars (regular and irregular), H-shaped, super H-shaped polymers and dendrimers. polyelectrolytes could also be distinguished upon their composition. Homopolymers are prepared by cross-linking of only one type of small ion or monomer, while copolymers are synthesized by cross-linking of two different types of monomer units.

\section{PREPARATIONS OF POLYELECTROLYTES}

To produce polymeric substances, free-radical polymerization is the most used industrial method, inclusive plastics, rubbers and fibers production. This method is comparatively tolerant to functional groups on the repeating units as ionic moieties, ligands, nucleophilic and electrophilic sites, acids and bases, and is possible to operate in various solvents. Numerous impurities, even water are not a genuine issue. This method does not require confusing procedures and modern types of gear to work under strict humidity-free situations. Polymerizations should even be possible straightforwardly in (water functioning as a solution, bulk, precipitation, suspension, or emulsion) given that oxygen is rejected. This method can be performed in a wide temperature range, relying on the monomer-initiator couple [14].

\section{A. Solution polymerization}

This polymerization procedure happens in solvents bearing both polymers and monomers. The rate of polymerization and the characteristics of the polymer thus obtained are controlled by factors like solvent type, $\mathrm{pH}$, temperature, surfactant, chain-transfer agent, and complexing agent [15].

\section{B. Bulk polymerization}

This polymerization procedure is done without solvents or diluents. By this technique, high-molecular-weight polymers can be prepared. Since, only monomers and, if necessary, initiators and catalysts are used so thus obtained polymers are extremely pure. The reusing and purification of solvents or dispersants and also the discard of liquid wastes are not required in this method, so economically and ecologically it has great advantages. Then again, significant challenges in running the procedure are frequently brought about by the evacuation of the heat of polymerization and the treatment of the thick reaction mixtures. Besides, polymerization in a profoundly viscous medium shows side responses, for example, chain transfers.

Bulk polymerizations are classified as homogeneous and heterogeneous reactions. Inhomogeneous bulk polymerizations, the polymer remains dissolved in the monomer, but in heterogeneous bulk polymerizations, the formed polymer is insoluble in its monomer [16].

\section{Precipitation polymerization}

In this method of polymerization, precipitation occurs as the polymer is prepared. Acetone, acetonitrile, dioxane, ethanol, tert-butanol, and Tetrahydrofuran (THF) are used as organic solvents for polymerization or aqueous organic media serve as solvents for monomers and non-solvents for polymers [17]. Toward the start of the process, the reaction mixture is homogeneous, though, during the procedure, precipitation of the polymer happens, and the process continues under heterogeneous conditions. Persulfates, perborates, benzoyl peroxide, Azobis iso butyronitrile (AIBN), and redox systems are used as initiators. As the reaction medium never gets viscous in precipitation polymerization, this process is done 10-30\% acrylamide solutions [18]. The obtained polymer, which is in high yield and has a generally high molecular weight, is filtered and dried.

\section{Suspension polymerization}

In the presence of stabilizers, when aqueous monomer solution is dispersed in an organic solvent and stirred mechanically, a suspended system is gotten [19]. The size of droplets in the aqueous monomer solution varies in diameter within the range of 0.1 to $5 \mathrm{~mm}$ for the preparation of dispersion medium, hydrocarbons (aliphatic or aromatic, or their mixtures) with carbon number 6-10 can be used as the organic medium. For initiation of polymerization, UV or gamma radiation can be used, or even common initiators are enough. The factors affecting the suspension may be the hydrophile-lipophile balance of the stabilizer, its distribution between the aqueous and organic phases, and temperature. The nature of the stabilizer and is concentration determines the rate of polymerization and their molecular weight [15]

\section{E. Emulsion polymerization}

This polymerization requires the charging of the reactors with a solution of emulsifier in an organic medium. During this, the aqueous solution containing 20-60\% monomer concentration is scattered in an organic solvent by continuous stirring. The solution of the emulsifier is cleansed by nitrogen and thermostated at $30^{\circ} \mathrm{C}$ to $60^{\circ} \mathrm{C}$. At that point, the solution of the initiator is mixed with the reaction mixture, and the polymerization is done for 3 to 6 hours. The concentrated latex can be obtained by heating under vacuum [7].

\section{MECHANISM OF POLYELECTROLYTES INTERACTION}

The various ways by which polymers interact with particles in aqueous solution decide the stability or instability of the dispersions. Stability refers that staying off the particles in a dispersed state for a long period rather than an aggregation of particles. The three primary processes that advance 
flocculation: polymer bridging, charge neutralization, and polymer adsorption, destabilized the particles in solid-liquid phases [20,21].

\section{A. Polymer bridging}

Polymer bridging refers to the destabilization process in which polymers particles get attached to form aggregates. There are two unique types of bridging which involves the negatively or positively charged polyelectrolytes and colloid particles. These involve polymer bridging between materials with the same charges or oppositely charged. Bridging of high-molecular-weight anionic and cationic polyelectrolytes respectively with negatively charged colloid particles are two kinds of the same and different interactions.

Bolto and Gregory [20] presented that macromolecules with linear chains of high-molecular-weight are the best for bridging and that charge density has a great effect on the bridging phenomena. On account of anionic polymers having high charge density, trouble would arise in adsorbing onto similarly charged particles, because of repulsion. However, repulsion within charged segments leads in the increment of chain length, so some level of charge is suitable which thusly should upgrade the bridging effect. Consequently, for the bridging flocculation of particles with a negative charge and anionic polymers, there is an ideal charge density.

\section{B. Charge neutralization}

A large portion of the naturally available polyelectrolytes are anionic, and positively charged polyelectrolytes adsorbed strongly on negatively charged polyelectrolytes by a charge neutralization method. Then again, the negatively charged polyelectrolytes adsorbed strongly on cationic polyelectrolytes by the same process. Thus, the positive charges along the polyelectrolytes chains of the cationic polymers are the best flocculant from the application perspective. The neutralization of charges and destabilization of the system is caused by the interaction of oppositely charged polymers with each other. For this situation, the role of the molecular weight of the polymer is less significant than the role of charge density of the polymer. Thus, polymers with low-molecular-weight and high charge densities successfully adsorb the oppositely charged polymers in solidliquid phases [20].

\section{Polymer adsorption}

Various kinds of interaction mechanisms are involved in the adsorption of polyelectrolytes on the dispersed particles. On broad classification, polymer adsorption mechanisms are of two types: physical and chemical adsorption, relying on the kind of interaction involved [22]. Weak interaction is usually physical adsorption and includes small energy changes. Chemical adsorption is strong interaction and covalent bonding among the adsorbate and surface particles is responsible for this adsorption.

\section{FACTORS AFFECTING THE MECHANISM OF INTERACTION}

Polyelectrolytes are polymer carrying positive or negative charge along the polymer chain and are water-soluble. These polymers are anionic or cationic depending upon the charge carried by them. They are accessible in a large range of molecular weights and charge densities. Polymers that do not bear any charges on them are also taken into account as polyelectrolytes, for example, homopolymers of acrylamide. These are known as non-ionic.

The elements influencing the selection of the proper PEs for a given procedure are [23-25]:

1. The characteristics of the substrate:

a) Organic/inorganic content

b) Net surface charge density

c) The solids content of the substrate

d) $\mathrm{pH}$ of the substrate

e) The Temperature of the system (Brownian motion)

2. The final product to be accomplished:

a) Quick separation of the solid substance from the liquid.

b) Clarity of the isolated liquid.

3. Dynamic and shear effects:

a) Mixing /conditioning of polymer and substrate

b) Nature of the shear forces related to the dewatering instrument employed.

\section{POLYELECTROLYTES IN SOLUTION}

In solution, polyelectrolytes ionize giving birth to a polyion having numerous charges, linked by a proportionate number of small counterions. PEs are generally soluble in aqueous solution and the discussion below primarily refers to polymers in water. A few polyelectrolytes are dissolvable in solvents other than water and their impacts have been studied in polar organic solvents such as dimethylformamide [26] There are some studies in which polyelectrolytes are dissolved in the binary mixed solvent media [27-34]. In the case of no ionization, the polymers act basically as a nonionic polymer.

\section{A. Chain expansion}

Polyelectrolytes are almost rod-like in pure water at low concentrations, but when salt is added, the degree of expansion decreases because the polymer charges are shielded from each other to some extent.

Also, chain expansion depends on the degree of neutralization of weakly acidic or basic polymer. An increase in charge density expands the chain smoothly for poly(acrylic acid), but the chain of poly(methacrylic acid) undergoes high expansion [35,36]. Ampholytic polyelectrolytes sometimes show different characteristics, and increasing salt concentration may expand chain length [37].

\section{B. Polyion-small ion interactions}

Ions formed by dissociation of PEs are not evenly distributed in the solution but remain in the neighborhood of polyion, creating an ionic environment. Many researchers have agreed on the approach of the Debye-Huckel theory of simple electrolytes, and some used the Poisson-Boltzmann equation to determine the electrostatic potential around the polyions. While some researchers consider polyion as a charged cylinder or worm-like chain and reported that above critical charge density, the counter ions condense. For uncondensed counterions, the Debye-Huckel theory is used. The most recent approach is the hypernetted chain integral equation and computer simulation method [38]. 


\section{The Donnan effect}

Donnan [39] in 1911, first described the effect which was seen due to the electrical neutrality in the solution and equal activities of dissociated components on either side of the membrane at equilibrium. Donnan effect is often suppressed by the addition of salt. This effect not only arises when a membrane is present but also when there is a presence of a boundary between polymer-rich and polymer-poor solutions.

\section{MOLECULAR WEIGHT DETERMINATION}

Molecular weights of polyelectrolytes can be determined in two ways, primary and secondary methods. Primary techniques involve colligative properties, static light scattering and sedimentary equilibrium, and these methods give absolute values. Viscosity and size exclusion chromatography (SEC) are secondary methods, which are more straightforward but calibration is required. Limiting the sedimentation coefficient and a limiting diffusion coefficient is also considered as secondary methods. However, by combining the two can provide absolute values.

Above mentioned methods require the aqueous solution of PEs and it should be 'molecular' and 'dilute'. Some PEs tend to assemble in solution and the transition of solution from dilute to semi-dilute of some commercial PEs of very high molecular weight fall in the range of concentration generally used for the experiment, so much care is required while preparing the solution.

For primary methods, the exact weight concentration of the PEs must be known. Moisture and impurities both should be taken under consideration while determining molecular weight. For example, commercially available sodium (polystyrene sulfate) (NaPSS) contains about $10 \%$ of moisture by weight and $40 \%$ inorganic sulfate [38].

The presence of salt is usually required for above-mentioned methods, but the excess quantity of salt may lead to phase separation and salt with divalent ions promote phase separation more effectively. One of the popular methods for determination of the average molecular weight of polyelectrolyte from viscosity measurement was found in the literature [40].

\section{CHARACTERIZATION OF POLYELECTROLYTES}

Properties of PEs are characterized based on their macromolecular and electrochemical characteristics [41].

\section{A. Macromolecular characterization}

\section{a. Chromatographic techniques}

Field flow fractionation, electrophoresis and SEC methods are used to characterize the macromolecular properties of PEs.

\section{b. Osmotic pressure}

The vapor pressure technique is used to determine the molar mass of polyelectrolytes. Due to the dissociative nature of PEs, their osmotic pressure varies frequently.

c. Light scattering techniques

In the solution, largely employed methods to characterize PEs are light scattering. Complete information on the size of particles, shape and mass of the dispersed matters, particlesolvent interaction and polydispersity can be known from this method.

\section{d. Ultracentrifugation}

This analytical technique is used to determine the molar mass of PEs in the range of 100 to $10^{8} \mathrm{~g} / \mathrm{mol}$. The sedimentation of macromolecules occurs when a centrifugal force acts on PEs solution at higher velocity. The molecular weight and sedimentation velocity are related to each other.

\section{B. Electrochemical characterization \\ a. Potentiometric techniques}

These techniques are used to determine the activities of $\mathrm{H}^{+}$ ions, using selective and reference electrodes. To characterize PEs, the common calculations involve $\mathrm{pH}, \mathrm{pKa}$ and degree of dissociation.

\section{b. NMR spectroscopy}

To determine the component involved in PEs, this method is employed. Extra information regarding molecular dynamics can be known by this technique.

\section{APPLICATION OF PES}

\section{A. Drinking water treatment}

To make natural water potable; the color, odor, taste, scaleforming matters, corrosive particles and solid substances should be removed to the required healthy level. This process includes removable of bacteria, algae, viruses, soluble and insoluble matters from natural water. To remove the latter two substances cationic polyelectrolytes of low molecular weight and high charge density are used [42].

\section{B. Sewage treatment}

The main issue in sewage treatment is to remove suspended solids from water and bioactive substances from thus obtained water. Polyelectrolytes are mainly used in the sludge dewatering step but also can be used in different stages of sewage treatment. Sewage sludge contain a higher content of suspended solids than that of naturally occurring water, so a high molecular weight PEs like poly(acrylamide) is used [42].

\section{Industrial raw and processed water treatment}

The methods to remove solid particles from industrial water involve the same techniques as for potable water treatment, the cationic PEs with high charge and low molecular weight is used [42].

\section{Papermaking}

Polyelectrolytes have various uses in paper or paper board making. Improving retention and drainage on the paper machine, improving dry and wet-strength of paper can be done by PEs [42].

\section{E. Mineral processing}

Flocculants facilitate the thickening of froth and clarification steps by which solids and liquids can be separated. In metallurgy, gangues are separated as a solid phase from the minerals remaining dissolved in the solution. The coal industry used both cationic and anionic PEs along with some natural polymers [7]. Polyelectrolyte with high charge density and high molecular weight, like hydrolyzed poly(acrylamide) (HPAM) is utilized to separate red mud from dissolved alumina to extract Al-metal form it's Bauxite ore [43]. 


\section{F. Enhanced oil recovery (EOR)}

In the EOR process, high molecular weight Hydrolyzed Polyacrylamides (HPAM) are used to increase the viscosity of water above the oil layer and can enhance the sweep efficiency during recovery. Polymer flooding involves the injection of PEs solution into the oil well to remove the oil of lower viscosity [44].

\section{G. Drilling fluid additives}

The main objective of drilling mud is to enhance the efficiency and rate of drilling, but not destroying the capacity of the well. PEs are either used to increase or decrease the viscosity of mud under the drilling shear conditions. Polyacrylamides or polyacrylates of low to medium molar mass are used as fluid additives to prevent the separation of liquid from gel [42].

\section{HISTORY OF POLYELECTROLYTE COMPLEXES(PECS)}

Since the beginning of the 1930s, PECs have attracted researchers through the research of Bungenberg de Jong et. al. who obtained some colloidal complexes after the interaction of some natural polymers in water, which is known as complex coacervates [45]. Since the beginning of the 1960s, insoluble synthetic PECs were obtained with several high linear charge density. Michaels et. al. [46] broadly described a large number of characteristics of such complexes, which includes the swelling and plasticizing characteristics in aqueous solution.

Kossel [47] in 1896, for the first time, realized the role of electrostatic interactions on the complexation of natural polymers, he presented that the electrostatic forces were the principal cause for the phase separation in the solution containing oppositely charged proteins and carbohydrates. But, much intense research and development of PECs only begin in 1961, when Michaels et. al. synthesized and characterized stoichiometric complexes of synthetic polymerpoly(4-vinylbenzyltrimethylammonium chloride) associated with NaPSS [48].

\section{POLYELECTROLYTE COMPLEXES (PECS)}

The term polyelectrolyte signifies a class of macromolecular compounds, which gets aggregated spontaneously or can be made to aggregate to obtain a large amount of basic charges dispersed along the macromolecular chain, when gets dissolved in an appropriate polar solvent, usually water [49]. The ability to form assemblies with appropriate partner species is a significant characteristic of water-soluble polyelectrolytes. The aggregation of solutions (in water) of polyanions with polycations or cationic surfactants gives water-insoluble precipitates so-called polyelectrolyte complexes (PECs) or polyelectrolyte surfactant complexes (PESCs) [50]. The system gets separated into a dilute and concentrated complex coacervate phase because of its dependence on various factors, or it might also form a moreor-less compact precipitate or gel. The PECs can likewise remain in solution. As the electrostatic attraction is the main attractive force, yet other forces like hydrogen bonding, dipole-dipole interactions and hydrophobic interactions usually play an important role in deciding the final structures $[51,52]$. Since PECs are well tolerated, biocompatible and sensitive to changes in natural conditions, they show a clear point of interest in the medical field, like for controlling drug release. The degree of ionization of each of the polycations and polyanions, the charge distribution over the PEs, the concentration of the PEs, the ratio of mixing, the nature and position of the ionic groups, the molecular weight of the PEs, the flexibility of the polymer chain, temperature, ionic strength and $\mathrm{pH}$ of the reaction medium determine the synthesis and stability of PECs [53].

Generally, the backbone chains of polycations and polyanions are irreconcilable and mostly repel one another. However, complexation between polyions could occur because of the polymer friction charge. The polymer/macromolecule/PE backbone repulsion is significant when the friction charge is low, as indicated by the Flory- Huggins interaction theory. Under this situation, the solution isolates into biphasic interfaces, each consisting of one of the polymers significantly. Under the influence of medium friction, the equilibrium condition can be a mesophase where the two PEs just isolate infinitesimally. The electrostatic force of attractions among the polymers imposes and they get precipitated out to form PECs for the high charge fraction [13].

In contrast with other polymers, PECs have peculiar characteristics. They are insoluble in almost all generally used common solvents. Based on the moisture percentage, their elasticity differs. PECs become hard and fragile under dry conditions, while they become elastic under wet conditions. Macroparticles cannot pass through the PECs but are permeable to all electrolytes.

Not only the chemical composition of the polymers (their molecular weight, stereochemical fitting, charge densities, etc. but also the secondary experimental conditions like the concentrations of the polyelectrolytes before mixing, their mixing ratio, ionic strength of the solution, mixing order, etc., influence the characteristics of PECs [51, 52].

The formation of PECs unavoidably prompts lost translational and conformational entropy of the polymer chain, which must be compensated if polymerization is to occur. During the formation of the first bond between two oppositely charged polyelectrolytes, entropy loss is largest but is very small for other neighboring bonds. The change in enthalpy per bond because of the reaction between monomers is usually constant, and at a certain chain length or sequence length, the formation becomes energetically favorable [54, 55]. Interactions like Van der Waals forces make a decent sterical fit among the polymers, which is essential for complexation to happen, promoting greater demands on the chemical structure and tacticity of the polymer. The PECs formed have properties like that of crystals and their degree of order is high, and have a quite a dense structure. These restrictions are presumably the primary factors behind the modest number of such stereocomplexes known as of not long ago [54].

A wide scope of utilization in various technological and scientific fields viz. medication, drug storage, biotechnology, cell culture, biomaterials, biomedical, beautifiers, etc. are allowed to PECs, because they can be formed with the various number of structures and properties [41]. PECs have gained interest in pharmaceutical and biomedical exploration 
because they are biodegradable, biocompatible and nonpoisonous [56].

\section{SYNTHESIS OF PECS}

Although PECs can be obtained by the reaction between macromolecules due to a series of secondary forces of attraction, the generally obtained complexes to deal with are those formed by the aggregation of polycations and polyanions. The effect of various attractive forces should be taken into consideration, even in these complexes.

In its early stage, the process of formation of PEC can be observed as the total influence of two oppositely acting processes [51], namely:

i) Electrostatic charge compensation guides polyanions and polycations to complexation and this happen regarding co-operative impacts initiating conformational changes helpful for mutual charge compensation.

ii) A 'chaotic' charge assembly of oppositely charged polyelectrolytes with only partial mutual charge compensation and an extensive number of ionic sites still charge compensated by Low Molecular Weight (LMW) counter-ions.

The general process of PEC synthesis includes three main steps:

(i) Random primary complex formation

(ii) Ordered secondary complex (Intra complex) formation

(iii) Inter complex aggregation

The initial step continues with the formation of secondary attractive forces, for example, Coulomb's forces following the combination of polycations and polyanions solution. This process is very fast. The subsequent step occurs within an hour and includes the arrangement of new bonds as well as the remedy of the deformation of the polymer chains to characterize new arrangements of the polymer chains. The last step includes the assembly of secondary complexes, primarily through hydrophobic interactions. Thus-obtained PECs are not soluble in common solvents, and the polymer components in the assembly are a molar ratio of unity [57]. The final assemblies of the PECs are not soluble in ordinary solvents.

\section{A. Polyelectrolytes using new synthetic methods}

Late improvements in the manufacture of polyelectrolytes are featured, concerning the behavior of ionic gatherings, polymer backbones, manufacturing ways, and extra usefulness given to polyelectrolytes. Laschewsky [58] gives the specific consideration to strong polyelectrolytes, and recent techniques for controlled polymerization $(\mathrm{CP})$, called click reactions, which have empowered the novel specification of polyelectrolytes. Here, the more and more developing strategies of the so-called CP, specifically of the controlled free-radical polymerization (CFRP) techniques, have given a significant push to make new polyelectrolytes recently.

\section{a. Synthesis by 'click chemistry':}

The term 'click chemistry' was first-authored by K.B. Sharpless in 1998. Click chemistry is another type of organic compound formation, or, perhaps more precisely, the revitalization of an old style of organic synthesis whose reason for existing is to quicken the revelation of substances with helpful properties, new medications being the limelight. It is not a specific reaction but describes the natural process of synthesis [59]. Click chemistry combines characteristics like modularity, insensitive to solvent parameters, high yield, insensitivity towards oxygen and water, regiospecificity and enormous thermodynamic driving force to support a single reaction product [60].

Presently, the most popular "click" reaction is the copper(I)catalyzed azide-alkyne 1,3-dipolar cycloaddition [61].

\section{b. Synthesis by controlled free radical polymerization (CFRP):}

The CFRP strategies [62] have reformed the manufacture of polyelectrolytes in the past decades. Because of the greater resistance of radicals toward electrophiles just as nucleophiles, FRP is fated for manufacturing charged polymers, also in the aqueous medium, which does not require protecting groups or additional modification of polymers that change the well-structured neutral precursor polymer into the required polyelectrolyte. The CFRP methods have in this way given immediate access to polyelectrolytes with beforehand inconceivable characteristics, for example, predefined molar masses, limited molar mass conveyances and very much characterized (and functional) end groups. Significantly, CFRP is different in permitting the preparation of block copolymers, in which each block is a statistical or even random copolymer, as shown for complex polyelectrolytes effectively, utilizing the reversible expansion discontinuity chain move polymerization (RAFT) strategy [63]. RAFT is seemingly the most adaptable strategy among the different CFRP procedures amount manufacturing the charged polymers.

\section{B. Layer-by-Layer (LbL) assembly}

Around a hundred years ago, the investigation of polyelectrolyte complexes started [45] but is being revived a short time ago on account of many different types of work that require immense knowledge of the field. One such line is the layer-by-layer (LbL) aggregation of electrolyte units, invented by Decher [64], which leads to many possible applications in the fields of catalysis, membranes and biomedicine.

Using this technique, consecutive layers of oppositely charged polymers are saved onto a solid substrate, for example, silica particles [65], sodium poly(styrene sulfonate)/poly(allylamine hydrochloride)/poly(diallyl dimethyl ammonium chloride) [66]. The multilayers are subsequently stabilized by the electrostatic interactions present in the PEC. Amorphous natured multilayers can be blend with charged substances, for example, drugs and proteins. Pérez-Anes et al. [67] effectively unite chitosan and poly- $\beta$-cyclodextrin over the surface of titanium and stacked with gentamicin to aim perioperative infections by $\mathrm{LbL}$ aggregation.

The benefit of the LbL technique is that the obtained PECs are stable and the utilization of the layers involves coating matters [68], this procedure is slow and a smooth surface is required for the aggregation of the following polymer layer $[65,68]$. 


\section{The solution method}

This is generally utilized strategy for PEC formation, in which polymers are dissolved in water or solvents before they are combined. Limiting the utilization of organic solvents and focusing on water as the main solvent, in most cases, gives a stimulus for utilizing PECs in pharmaceutical businesses. To encourage the PEC synthesis, which happens by electrostatic attraction between polycations and polyanions in solution, the polymers must be charged [23].

It is a simple technique for the formation of PECs because of the precipitation of the complex immediately after formation, yet a portion of the polymers and medication are lost in the supernatant solution during formation [23, 69].

\section{Melt Extrusion}

This process includes an extruder that liquefies and combines the polymers and excipients utilizing heat, stacked into the extruder. The utilization of solvents to prepare the complexes having drugs by this method does not need the utilization of solvents. The crystal lattice should not be broken, so the medication is molecularly scattered inside the polymer, which prompts the upgrade of its solubility [70,71]. The degree of formation of intermolecular reactions is determined by the solubility of the drug with the polymers. An increase in drug bioavailability is led by the melt extrusion, since it gives amorphous and stable solid scatteredness of the medication within a polymer. A drug with controlled discharge and better dissolvability can be accomplished [72].

It is a nonstop method of synthesis and the addition of solvent is not needed [70, 71], though generally, it requires low melting point polymers [72].

\section{FACTORS AFFECTING THE FORMATION OF PECS}

The quality and structure of PECs mainly depend on three parameters:

i) Structure parameters

ii) Media parameters

iii) Preparation parameters

Structure parameters

- The ratio of positive and negative charges

The ratio of charges of polycations and polyanions used in the preparation of PECs must be studied. This charge ratio is represented by $z$. The stoichiometric charge ratio is represented by $\varphi$. S-PECs $(\varphi=1)$ are highly hydrophobic due to mutual screening of the charge and are precipitated out from the aqueous solution. If N-PECs $(z \neq 1)$ is prepared, then the overcharging effect due to an excess oppositely charged polyelectrolytes are observed [73].

Hugerth et al. [74] investigated the effect of charge density on PEC formation between carrageenan and chitosan with varying concentrations of deacetylation. They observed the formation of PECs with a stoichiometric charge ratio of unity. Carrageenan is available in helix-helix aggregation, then PECs are formed with a charge ratio below unity w.r.t. chitosan.

\section{- Charge density}

Dautzenberg et al. [75] studied the effect of charge density on the process of PEC formation by combining a cationic copolymer of diallyl dimethyl ammonium chloride
(DADMAC) and N-methyl-N-vinyl acetamide (NMVA) with sodium poly(styrene sulfonate) (NaPSS). They observed that the difference in charge density does not cause a real chance to control the degree of swelling of polyelectrolyte complex structures under particle aspects.

Okay et al. [76] investigated the elastic modulus of polyelectrolytes hydrogels formed with acrylamide and 2acrylamino-2-methyl propane sulfonic acid (AMPS) at various charge densities. They observed the increase in the modulus at the beginning but decreased continuously afterward. This result represents two opposite effects of charged groups: modulus increases due to the formation of additional crosslinks and decreases because of the electrostatic interaction of charged groups on elastic free energy.

- The Molecular weight of the polyelectrolytes Sui et al. [77] reported the effect of molecular weight on the synthesis of polyelectrolyte multilayers by combining NaPSS, poly(DADMAC) and poly(4-vinyl pyridine) (P4VP) with narrow mass distributions in the presence of added salt $\mathrm{NaCl}$. They found unusual multilayering characteristics for polymers in the range of $10^{4} \mathrm{Da}$ molar mass even if the polymers are highly charged. In this range of molar mass, the surface polyelectrolyte is stripped off by its oppositely charged partner.

De Vasconcelos et al. [78] studied the effect of the molecular weight of poly(methacrylic acid) (PMAA) on the formation of PECs based on chitosan. They reported an increase in solubility of the complexes as a function of the molecular weight of PMMA, which may be due to the lower presence of carboxylic groups at the outer parts of PMMA coils due to an increase in molecular weight.

\section{Media parameters}

- Polyelectrolyte concentration

Shovsky et al. [79] investigated the formation and stability of PECs as a function of the polyelectrolyte solution concentration. They used NPSS as a polyanion and copolymers with various molar ratios of poly(methacryl oxyethyl trimethyl) (PMETAC) and nonionic poly(ethylene oxide)methyl ether (PEOMEMA) as polycations. They observed that even $25 \%$ of the PEO side chains were sufficient to prevent precipitation. When the PEO side-chain content was increased (50\% and $75 \%$ ), small, and watersoluble complexes were formed.

\section{- $\mathrm{pH}$}

The alteration of chitosan into $\mathrm{N}$-carboxyethyl chitosan (CECh) permits the formation of PECs in a $\mathrm{pH}$ range in which chitosan is not able to form complexes. The complex between CECh and poly[2-(dimethylamino)ethyl methacrylate] (PDMAEMA) in a $\mathrm{pH}$ range around 7 was obtained by Yancheva et al. [80]. They observed that the grouping of four tertiary amino groups of PDMAEMA makes complex formation with CECh possible both in neutral and in alkaline media.

Sakharov et al. [81] studied the enzymatic reaction of polyaniline (PANI) and PSS under the effect of $\mathrm{pH}$ of the 
medium in an interval of 2.5-4.5. The optimum $\mathrm{pH}$ for the synthesis was 3.5 .

- The Ionic strength of the reaction medium

The ionic strength of the reaction medium has a significant effect on the preparation of PECs. Huang et al. [82] observed a marked weakening of the complexation between $\mathrm{O}$ carboxymethyl chitosan (O-CMC) and sodium alginate (SAL). The highest complexation occurred in the absence of $\mathrm{NaCl}$. The increase in ionic strength decreases the average diameter of the colloid, which could be related to the increase in chain flexibility [83].

- Salt concentration

Dragan et al. [84] studied the effects of low-molecular-weight (LMW) salts like $\mathrm{NaCl}, \mathrm{NaI}$ and $\mathrm{Na}_{2} \mathrm{SO}_{4}$ on the formation of PEC between N,N-dimethyl-2-hydroxypropylene ammonium chloride units in the main chain $\left(\mathrm{PCA}_{5}\right)$ and poly(sodium acrylate) (PSA). When the concentration of $\mathrm{NaCl}$ increased from 0 to $2 \mathrm{M}$, the decrease in the molar ratio corresponding to the endpoint was observed. At equal concentrations of LMW salts, PEC separation was viewed in the order of $\mathrm{R}_{\text {sep }}\left(\mathrm{SO}_{4}{ }^{2-}\right)<\mathrm{R}_{\text {sep }}\left(\mathrm{I}^{-}\right)<\mathrm{R}_{\text {sep }}\left(\mathrm{Cl}^{-}\right)$.

Dautzenberg et al. [75] studied the formation of PEC between NaPSS and the DADMAC/NMVA copolymer in pure water to succeeding the addition of salt $(\mathrm{NaCl})$. The presence of $0.01 \mathrm{~N} \mathrm{NaCl}$ has a significant effect on the formation of PEC; the level of aggregation was strongly decreased by up to 2 orders of magnitude. The almost the same pattern was also observed for PECs in $0.1 \mathrm{~N} \mathrm{NaCl}$.

\section{Preparation parameters}

- $\quad$ Mode of mixing

The prepared PECs are hoped to rely on the mixing type, protocol and instrument used. The effect of combining the process of poly(allylamine) (PAA) and poly(acrylic acid) (PAC) by comparison of jet mixing with generally employed colloid titration was studied by Ankerfors et al. [85]. For both LMW polyelectrolytes, small-sized PECs were obtained, but for high-molecular-weight polyelectrolytes, the size of the PECs first decreased with increasing mixing time until a minimum was reached and then rise again. Smaller PECs by jet mixing and larger PECs by colloid titration were obtained for larger polyelectrolyte, letting the mixing time to control the size of PECs.

\section{- $\quad$ Mixing order}

The order of addition of polyelectrolyte has been reported by many researchers, by mixing polyelectrolyte solutions slowly with each other [86]. The comparison between the slow dropwise additions with fast one-shot addition for the preparation of CHT-DS PECs was done by Schatz et al. [53]. PECs with a small radius and greater stability was obtained from the rapid process compared to the slow process. The slow process is sensitive to the order of mixing which is in contrast to fast one-shot mixing.

\section{- Mixing ratio}

This is the ratio of oppositely charged polyelectrolytes combined to obtain the PECs. The ratio not only affects the size and charge of PECs but also their biological activity [87]. Gernandt et al. [88] observed the opposite trends of aggregation while raising the mixing ratio than that of forming PECs in pure water (salt-free). This characteristic was explained by secondary assembly due to the shielding of the stabilizing shell of the PEC formed by the excess component [89]. This shell becomes thinner and aggregation occurs in the presence of salt due to an increase in the ratio of addition and consumption of excess component.

\section{STRUCTURE OF PECS}

Relying on different factors like charge ratio, degree of polymerization and the structural characterization of the starting polyelectrolytes, the structure of PECs is divided into two types: stoichiometric water-insoluble and nonstoichiometric water-soluble PECs [90].

\section{A. Stoichiometric water-insoluble PECs}

These PECs are electrically neutral and are precipitated out of the solution. They have strong electrostatic attraction between the polymers and these polymers are a 1:1 molar ratio [70, 91]. These PECs are insoluble in water and other organic solvents but can swell in aqueous solutions [92]. Depending on the properties of polyion groups, molecular weights and reaction conditions; stoichiometric PECs are of two types: ladder-like structure and scrambled-egg model [90].

\section{B. Nonstoichiometric water-soluble PECs}

These complexes are obtained due to non-stoichiometric ratios of polymers, these PECs are water-soluble and their turbidity level determines their concentration in the solution [93]. A host polymer with a longer chain and greater amount then a guest polymer facilitates the PEC. Thus, the obtained PEC is uniformly dispersed in water and its formation is reversible.

\section{TYPES OF PECS}

PECs formed by the interaction of oppositely charged polyelectrolytes, while they are in solution, are of three different types [94, 95]:

- Water-soluble: These PECs are obtained when starting polymers are with weak ionic groups and their molar masses bear large differences and are mixed non-stoichiometrically. These PECs are soluble in macroscopically homogenous systems.

- Turbid colloidal PECs: These PECs are formed by the aggregation of polyelectrolytes at low or medium ionic strength and in very dilute solutions in non-stoichiometric proportions. These systems are seen in the transition range to phase separation.

- Two-phase system PECs: These PECs are synthesized by the interaction of high and comparable weight polyelectrolytes in a very highly concentrated solution. These complexes are easily separated as solid substances after washing and drying.

Based on the types of reacting polyelectrolytes, PECs are classified as:

- PECs formed by interacting with natural polyelectrolytes

Many PECs were prepared using chitosan with natural polyanions such as carboxymethyl cellulose, alginic acid, 
carboxymethyl dextran, dextran sulfate, pectin, carrageenan, heparin and xanthane. To study the degree of complexation of lysozymes with deacetylated chitosan, Colfen et al. [96] implement analytical centrifugation for the first time.

To develop functional characteristics of proteins, such as foaming aggregation or gelation, the interaction between oppositely charged proteins was reported. The concentration of proteins, the ionic strength and $\mathrm{pH}$ of the solution determine the complexation and quantity of complex formed [55]

- PECs formed by interacting with synthetic polyelectrolytes

Almost all of the PECs formed by synthetic polymers utilize conductometric, potentiometric, or turbidimetric titration. By complexation of poly(vinyl-benzyltrimethylammonium chloride) (PVBTAC) with PMAA, three different types of PECs were formed [97].

The stoichiometric investigation of the reaction between polycations and polyanions, such as protonated polyethylene imine, PVBTAC, ionene, and polyanions such as PSA, KPSS were done and was reported that PEC was formed by almost stoichiometric reactions. The sigmoid type adsorption shown by PEC is identical to the adsorption nature of hydrophilic substances [98].

- PECs formed by reacting natural and synthetic polyelectrolytes

The complex formation between proteins and synthetic polymers was observed by phase separation as a complex coacervate or a solid precipitate, and it was seen for complexation between potassium poly(vinyl alcohol sulfate) and carboxyhemoglobin in the presence of poly(DADMAC), lysozyme and PAC, lysozyme and PMAA, RNA polymerase and poly(ethylene imine), poly(DADMAC) and bovine serum albumin [99].

- Protein-polyelectrolyte complexation

The strong interaction between a protein with both natural and synthetic polymers results in the amorphous precipitate, coacervate, gels, fibers or soluble complexes. The availability of charge sites on the protein's surface, the $\mathrm{pH}$ of the medium, the type of polymers, ionic strength and amount of polymer determines the efficiency of complexation. The structural variation of polypeptides related to PECs formation was reported for poly(L-glutamic acid), poly(ethylene imine) and poly(L-lysine) [55].

- Polyions and surfactant complexation

PECs formed by polyions-surfactant complexation are very exciting because they have an attractive resemblance to biological aggregations. The complexation for ionic surfactants above the critical micelle concentration is a result of coulombic interaction between the polymer and the charged micelle [55]. The complexation between PSS and various alkyl trimethylammonium derivatives was formed by precipitation in aqueous solution and after redissolving in polar organic solvents; they show characteristics of polyelectrolytes [100]. There were also studies of NaPSSCTAB(cetyl trimethyl ammonium bromide) in the binary mixture[101, 102].

\section{PROPERTIES OF PECS}

Since the characteristics of the beginning materials are unique to those of PECs, and this encourages the investigation of their production. Despite many methods, some of the methods that identify such contrasts are potentiometry, conductometry, turbidimetry, viscometry, calorimetry, sedimentation, dynamic flow birefringence, light scattering, NMR spectroscopy, electronic spectroscopy, chromatography and even electron microscopy.

To accomplish a more extensive business of PECs, the numbers of nitty-gritty information on their characteristics is required. It is commonly accepted that PECs have special features because the principle interaction forces are strong Coulomb forces and their electrostatic nature can undoubtedly be altered by varying just their composition [103]:

1) Physicochemical properties

2) Good transparency

3) Selectivity for ion sorption

4) ion-exchange properties

5) Electrical properties

6) Transport properties

7) Good anti-coagulant properties

PECs, which are made out of a strong polyacid and a strong polybase, are not soluble in regular organic and inorganic solvents. They are just dissolvable in a definite medium, for example, water/water-soluble organic solvents/micro salts, such as water/acetone/ $\mathrm{NaBr}$ [46, 103-105].

PECs have remarkably large and governable penetrability in water and low-molecular-weight solutes. The commercial cellophane membrane shows lower permeability towards low-molecular-weight solutes than that of complex membranes [106]. The permeability of membranes made from PECs derived by mixing polyacids and polybases with equimolar composition is generally more to water and urea [107].

Biologically derived solids show a closer relation to PECs based on electrical characteristics. Not too many artificial polymers, incredibly high relative dielectric constants at low frequencies and the dispersion qualities of salt-containing PECs are not observed [108]

At $22^{\circ} \mathrm{C}$, the refractive index of homogeneous PECs containing $40-80 \%$ gel water is expressed by

$\mathrm{n}=1.294+0.336(1-\alpha)$

where $\alpha$ refers to the gel-water content as a weight fraction [103].

\section{CHARACTERIZATION OF PECS}

The characterization of PECs primarily involves the physicochemical, morphological and solid-state analyses of the complexes [95]. Optical density, the weight of dried complexes, calorimetry, optical microscopy, dynamic light scattering (DLS), differential scanning calorimetry (DSC), Xray diffraction, SEM, dialysis bag method, orbital flask method, stability study, thermal analysis, potentiometric and turbidimetric titrations, ultracentrifugation, $\mathrm{pKa}$, viscosity, and gel electrophoresis were used to determine the complexation $[13,109,110]$. 


\section{APPLICATIONS OF PECS}

\section{A. PECs in drug delivery}

PECs have gained much attention in recent years because of their possible applications in various fields. It can be used in drug delivery systems. Hu et al. [111] investigated the controlled burst of magnetic polyelectrolyte capsules for drug transport. The microcapsules prepared by the Layer-byLayer (LbL) procedure utilizing $\mathrm{Fe}_{3} \mathrm{O}_{4} / \mathrm{PAH}$ are magnetic sensors. Design quality, micro-structural development and related discharge characteristics of fluorescence dyes and doxorubicin were methodically researched. The test results indicated that the availability of the magnetic nanoparticles in the covered structure permitted the covered structure to advance from nanocavity improvement to a definite break of the cover under the influence of the given magnetic effect of various periods.

Wang et al. [112] studied the new combined effect of adsorption by porous $\mathrm{CaCO}_{3}$ microparticles and encapsulated PEM films for continued medication conveyance through LbL self-aggregation. The powdered ibuprofen (IBU) stacked in the pores of the $\mathrm{CaCO}_{3}$ microparticles had a faster discharge rate in the gastric fluid than in the intestinal fluid when compared with the crystalline uncovered IBU; however, the PEMs gathered on the drugs stacked particles by LbL decreased the rate of discharge in both liquids.

\section{B. Dialysis/ultrafiltration membrane}

Neutral PECs are used for the desalinization of brine [46] and, dialysis/ultrafiltration membranes to purify and/or concentrate aqueous solutions having colloids, micro or macro-solutes in it. This is due to their extremely high permeability to water. The permeability of the neutral complex membrane is nearly 15 folds higher than that of cellulose diacetate and 10-50 times higher than regenerated cellulose membranes.

Comparison to primitive dialysis membrane, for example, cellophane; controlled microstructure PECs membrane possesses 5-10 times higher efficiency. So, interest has been developed in the application of PECs membrane in artificial kidneys and artificial lungs [107].

\section{Medical and surgical prosthetic materials}

Because of the close similarity of PECs with connective tissue like collagen and their extraordinary permeability to water and other microsolutes, has developed the interest of using PECs as prosthetic materials since the 1960s. In recent years, PECs have understudy to stop the expansion of the weak wall of the artery. Also, the coating of PECs has been used in different machines through which blood gets circulated, for example, heart valves, heart-lungs machines, etc., to stop blood clotting over their surfaces [46].

\section{PECs in gene delivery}

The utilization of PECs in gene therapy depends on their biocompatible design for in vivo delivery of non-viral vectors packed with therapeutic genes. The so-called PECs are formed when DNA is condensed by polycations, and they have gained remarkable attention in gene delivery, where the primary dare is to develop riskless and efficient non-viral vectors [113].

\section{E. PECs in protein and peptide delivery}

The complex formed between bovine serum albumin (BSA) and synthetic PE was first reported PEC of this type, and since they have been widely used in food and biotechnology businesses. The main method for non-covalent bonding depends on the electrostatic attraction between positively charged polymers and negatively charged proteins/peptides, while amphiphilic polymers interact via both electrostatic and hydrophobic interactions [114].

\section{F. PECs as diagnostic and imaging agent}

PECs formed by grafting chitosan with gadolinium (Gd)/diethylenetriamine pentaacetic acid (DTPA) was developed by Huang et al. [115]. About $300 \mathrm{~nm}$ sized particles were produced when chitosan was complexed with dextran sulfate, electrostatically. In other ways, Gd was trapped ionically within PECs with gadolinium chloride $\left(\mathrm{GdCl}_{3}\right)$. From these two approaches, three types of particles were obtained, viz. Gd-loaded, Gd-DTPA conjugated, and PECs consisting of both ionically trapped Gd and Gd-DTPA grafts. The contrast-enhanced was observed accumulated rapidly in rat kidney, while some particles were also observed in the liver, and negligible particles were seen in other tissues. The determination of biodistribution and pharmacokinetics of PECs has been done by using contrastenhanced MRI, which is widely used as drug and gene delivery vehicles [115].

\section{G. Other applications}

As indicated by the fact that polyelectrolytes are broadly utilized as flocculants [116], they might be practically used in protein fractionation, which is significant in medication and clinical cure $[117,118]$. Also, the intermolecular complexes are used in particular extraction of organic and metallic ions; for example, $\mathrm{Cu}^{2+}$ ions are more successfully precipitated by the PECs than by one of its components [119].

PECs can be utilized to manufacture ultra-filtration films that can be utilized in artificial kidneys, artificial lungs whose proficiency is restricted by previously existing membrane materials that give significant protection from mass exchange [107].

\section{PROBLEMS OF PECS}

The manufacture of PECs, despite the specific level of development, still faces various uncertain issues. There are difficulties and still numerous new compounds that are yet to be found. Shortly, polyelectrolytes will not be explored by the desire of their own, but will be generally inspired by material angles; these results not only new ionic structures but progressively complex all around the molecular structures and geometry. Subsequently, there will be numerous chances, and require an unstoppable expansion of the extent of available polyelectrolyte structures.

\section{CONCLUSION}

The development of enthusiasm for the study of polyelectrolytes is expected essentially to the expanding utilization of these polymers as flocculants, stabilizers of scatterings, definite absorbents or adsorbents and as medication bearers. In a significant number of these applications, the creation of amphiphilic polymers, materials containing both hydrophilic and hydrophobic units with 
extraordinary morphology are of crucial significance. In this unique circumstance, the interaction between macromolecules offers broad uses and their capacity has not yet been completely achieved. Proceeding with research polyelectrolyte collaborations will undoubtedly advance the connections between the polymer and different sciences, specifically the connections with biochemistry.

\section{REFERENCES}

[1] The Science and Practice of Pharmacy. Remington $21^{\text {st }}$ Edition Volume I.

[2] H. Liu, L. Skibinska, J. Gapinski, A. Patkowski, E.W. Fischer, R. Pecora, Effect of electrostatic interactions on the structure and dynamics of a model polyelectrolyte. I. Diffusion, The Journal of Chemical Physics. 109 (1998) 7556-7566. https://doi.org/10.1063/1.477377.

[3] S. Dakhara, C. Anajwala, Polyelectrolyte complex: A pharmaceutical review, Syst Rev Pharm. 1 (2010) 121.https://doi.org/10.4103/0975-8453.75046.

[4] S. Amani, Z. Mohamadnia, Modulation of interfacial electrical charges in assembled nano-polyelectrolyte complex of alginatebased macromolecules, International Journal of Biological Macromolecules. $\quad 135 \quad$ (2019) 163-170. https://doi.org/10.1016/j.ijbiomac.2019.05.124.

[5] C. Tanford, Physical Chemistry of Macromolecules; Wiley: New York, NY, 1961

[6] A.V. Dobrynin, Solutions of Charged Polymers. In: Matyjaszewski K and Möller M (eds.) Polymer Science: A Comprehensive Reference, Vol 1, 2012, pp. 81-132. Amsterdam: Elsevier BV.

[7] A. Rabiee, Acrylamide-based anionic polyelectrolytes and their applications: A survey, J Vinyl Addit Technol. (2010) n/a-n/a https://doi.org/10.1002/vnl.20229.

[8] A. G.Ward, A. Courts, The Science and Technology of Gelatin; Academic Press: London, UK and New York, NY, 1977.

[9] R. J. Cox, Photographic Gelatin; Academic Press: London, UK and New York, NY, 1972

[10] R. Berendsen, H. Borginon, The Adsorption of Gelatin on Silver Bromide, The Journal of Photographic Science. 16 (1968) 194198. https://doi.org/10.1080/00223638.1968.11737461.

[11] H. Schiessel, The physics of chromatin, J. Phys.: Condens. Matter. 15 (2003) R699-R774. https://doi.org/10.1088/0953$8984 / 15 / 19 / 203$.

[12] J.J. Hayes, J.C. Hansen, Nucleosomes and the chromatin fiber, Current Opinion in Genetics \& Development. 11 (2001) 124-129. https://doi.org/10.1016/s0959-437x(00)00168-4.

[13] V.S. Meka, M.K.G. Sing, M.R. Pichika, S.R. Nali, V.R.M. Kolapalli, P. Kesharwani, A comprehensive review on polyelectrolyte complexes, Drug Discovery Today. 22 (2017) 1697-1706. https://doi.org/10.1016/j.drudis.2017.06.008.

[14] J. S. Poblete, Cationic polyelectrolytes. Synthesis, characterization and application in analysis and removal of arsenic. Chemical Sciences. Université de Grenoble, 2010, $1,7-138$.

[15] V.F. Kurenkov, V.A. Myagchenkov, Effects of reaction medium on the radical polymerization and copolymerization of acrylamide, European Polymer Journal. $\quad 16 \quad$ (1980) https://doi.org/10.1016/0014-3057(80)90030-0.

[16] D. Braun, H. Cherdron, H. Ritter, Polymer Synthesis: Theory and Practice: Fundamentals, Methods, Experiments, 3rd ed., Springer, Berlin (2001).

[17] J. C. Salamone, Polymeric Materials Encyclopedia, Vol. 4, CRC Press, Boca Raton, Florida, 7235 (1996).

[18] J. C. Salamone, Polymeric Materials Encyclopedia, Vol. 1, CRC Press, Boca Raton, Florida, 47 (1996).

[19] B. A. Fachri, Suspension polymerization of acrylamide in mixtures if methanol-water initiated by potassium persulfate. J. ILMU. DASAR, 2004, 5, 87-90.
[20] B. BOLTO, J. GREGORY, Organic polyelectrolytes in water treatment, Water Research. 41 (2007) 2301-2324. https://doi.org/10.1016/j.watres.2007.03.012.

[21] H. Stechemesser, B. Dobias, Coagulation and Flocculation, CRC Press, Boca Raton, Florida (2005).

[22] J. Gregory, Turbidity fluctuations in flowing suspensions, Journal of Colloid and Interface Science. 105 (1985) $357-$ 371. https://doi.org/10.1016/0021-9797(85)90309-1.

[23] S. Lankalapalli, V.R.M. Kolapalli, Polyelectrolyte complexes: A review of their applicability in drug delivery technology, Indian J Pharm Sci. 71 (2009) 481 https://doi.org/10.4103/0250-474x.58165.

[24] P. Molyneux, Water Soluble Synthetic Polymers: Properties and Behaviour, CRC Press, Boca Raton, Florida, 1984.

[25] M.F. Hoover, Cationic Quaternary Polyelectrolytes-A Literature Review, Journal of Macromolecular Science: Part A - Chemistry. 4 (1970) 1327-1418 https://doi.org/10.1080/00222337008081733.

[26] D.R. Scheuing, Size exclusion chromatography of polyelectrolytes in dimethylformamide, J. Appl. Polym. $\begin{array}{llll}\text { Sci. } & 29 & \text { (1984) }\end{array}$ https://doi.org/10.1002/app.1984.070290912.

[27] A. Bhattarai, P. Nandi, B. Das, The Effects of Concentration, Relative Permittivity and Temperature on the Transport Properties of Sodium Polystyrenesulphonate in Methanol-Water Mixed Solvent Media, J Polym Res. 13 (2006) 475-482. https://doi.org/10.1007/s10965-0069070-x.

[28] P. Nandi, A. Bhattarai, B. Das, Intrinsic viscosities of sodium carboxymethylcellose in acetonitrile-water mixed solvent media using isoionic dilution method, J. Polym. Sci. B Polym. Phys. 45 (2007) 1765-1770 https://doi.org/10.1002/polb.21093.

[29] D. Ghosh, A. Bhattarai, B. Das, Electrical conductivity of sodium polystyrenesulfonate in acetonitrile-water-mixed solvent media: experiment and data analysis using the Manning counterion condensation model and the scaling theory approach, Colloid Polym Sci. 287 (2009) 10051011. https://doi.org/10.1007/s00396-009-2055-7.

[30] A. Bhattarai, B. Das, Effects of Concentration, Temperature and Solvent Composition on the Partial Molar Volumes of Sodium Polystyrenesulphonate in Methanol -Water Solvent Media, J. Nepal Chem. Soc. 23 (1970) 82-88. https://doi.org/10.3126/jncs.v23i0.2100.

[31] A. Bhattarai, B. Das, Effect of Different Low-Molar Mass Electrolytes on the Viscometric Behaviour of Sodium Polystyrenesulfonate in Methanol-Water Mixed Solvent Media, Macromol. Symp. 366 (2016) 8-13. https://doi.org/10.1002/masy.201650041.

[32] A. Bhattarai, B. Das, Solvodynamic Properties of Sodium Polystyrenesulfo-nate in Methanol-Water Mixed Solvent Media in Absence and in the Presence of a Salt Using Viscometric Method, Macromol. Symp. 315 (2012) 5259. https://doi.org/10.1002/masy.201250507.

[33] A. Bhattarai, Interaction behavior of polyion-counterion for sodium polystyrene sulfonate, Data in Brief. 25 (2019) 104365. https://doi.org/10.1016/j.dib.2019.104365.

[34] A. Bhattarai, Electrical Conductivity of a Semidilute Polyelectrolyte in Mixed Solvent Media, Nepal Journal of Science and Technology. 9 (1970) 163 170.https://doi.org/10.3126/njst.v9i0.3182.

[35] A. Katchalsky, H. Eisenberg, Molecular weight of polyacrylic and polymethacrylic acid, J. Polym. Sci. 6 (1951) https://doi.org/10.1002/pol.1951.120060202.
$145-154$ 
[36] J.L. Koenig, A.C. Angood, J. Semen, J.B. Lando, Laserexcited Raman studies of the conformational transition of syndiotactic polymethacrylic acid in water, J. Am. Chem. $\begin{array}{llll}\text { Soc. } & 91 & \text { (1969) } & \text { 7250-7254 }\end{array}$ https://doi.org/10.1021/ja01054a008

[37] J.C. Salamone, I. Ahmed, M.K. Raheja, P. Elayaperumal, A.C. Watterson, A.P. Olson, Behavior of Polyampholytes in Aqueous Salt Solution, in: Water-Soluble Polymers for Petroleum Recovery, Springer US, 1988: pp. 181-194. https://doi.org/10.1007/978-1-4757-1985-7_11.

[38] P. M. Budd, Polyelectrolytes. Comprehensive Polymer Science, 215-228, 1989, Pergamon Press.

[39] F.G. Donnan, Theory of membrane equilibria and membrane potentials in the presence of non-dialysing electrolytes. A contribution to physical-chemical physiology, Journal of Membrane Science. 100 (1995) 4555. https://doi.org/10.1016/0376-7388(94)00297-c.

[40] A. Bhattarai, Determination of the average molecular weight of sodium polystyrenesulphonate from viscosity measurement, Sci World. 10 (2012) 17-19. https://doi.org/10.3126/sw.v10i10.6855

[41] J. Koetz, S. Kosmella, Polyelectrolytes and Nanoparticles. Springer, 2007.

[42] D.A. Mortimer, Synthetic polyelectrolytes-A review, Polym. Int. 25 (1991) 29-41. https://doi.org/10.1002/pi.4990250107.

[43] N.Vorchheimer, "Synthetic Polyelectrolytes," in Polyelectrolytes for Water and Waste-Water Treatment, W.L.K. Schwoyer, Ed., CRC Press, Boca Raton, Florida, 1 (1981).

[44] I. W. Sutherland, C. Kierulf, "Downhole Use of Biopolymers,' In the First Microbial Problems in the Offshore Oil Industry, Proceedings of the Institute of Petroleum, London, 93 (1987).

[45] H.G. Bungenberg de Jong, H.R. Kruyt, Coacervation (partial miscibility in colloid systems). In Proceedings Koninklijke Nederlandse Akademie Van Wetenschappen, 1929, 32, 849-856.

[46] A.S. Michaels, POLYELECTROLYTE COMPLEXES, Ind. Eng. Chem. 57 (1965) 32-40. https://doi.org/10.1021/ie50670a007.

[47] A. Kossel, Ueber die basischen Stoffe des Zellkerns., Hoppe-Seyler's Zeitschrift Für Physiologische Chemie. 22 (1897) https://doi.org/10.1515/bchm2.1897.22.2.176.

[48] A.S. Michaels, R.G. Miekka, POLYCATIONPOLYANION COMPLEXES: PREPARATION AND PROPERTIES OF POLY(VINYLBENZYLTRIMETHYLAMMONIUM) POLY(STYRENESULFONATE), J. Phys. Chem. 65 (1961) 1765-1773. https://doi.org/10.1021/j100827a020.

[49] I. Syed, I. Ahmad, P. Niveditha, Formulation and evaluation of polyelectrolyte complex-based matrix tablet of Isosorbide Mononitrate, Int J Pharma Investig. 4 (2014) 38. https://doi.org/10.4103/2230-973x.127739.

[50] H. Dautzenberg, W. Jäger, J. Koetz, B. Philipp, C. Seidel, D. Stscherbina, Polyelectrolytes, Hanser, Munich, 1994, $248 \mathrm{pp}$.

[51] B. Philipp, H. Dautzenberg, K.-J. Linow, J. Kötz, W. Dawydoff, Polyelectrolyte complexes - recent developments and open problems, Progress in Polymer Science. 14 (1989) 91-172. https://doi.org/10.1016/00796700(89)90018-x.

[52] V.A. Kabanov, A.B. Zezin, V.B. Rogacheva, N.V. Grishina, E.J. Goethals, M. Van de Velde, Makromol. Chem. $\quad 187 \quad$ (1986) 1151-1158. https://doi.org/10.1002/macp.1986.021870512.
[53] C. Schatz, J.-M. Lucas, C. Viton, A. Domard, C. Pichot, T. Delair, Formation and Properties of Positively Charged Colloids Based on Polyelectrolyte Complexes of Biopolymers, Langmuir. 20 (2004) 7766-7778. https://doi.org/10.1021/la049460m.

[54] R.H.G. Brinkhuis, A.J. Schouten, Thin-film behavior of poly(methyl methacrylates). 5. Characteristics of the poly(methyl methacrylate) monolayer stereocomplexation process, Macromolecules. 25 (1992) 2732-2738. https://doi.org/10.1021/ma00036a026.

[55] V.A. Kabanov, I.M. Papisov, Formation of complexes between complementary synthetic polymers and oligomers in dilute solution review, Polymer Science U.S.S.R. 21 (1979) 261-307. https://doi.org/10.1016/0032 3950(79)90245-4.

[56] V. Boeris, B. Farruggia, B. Nerli, D. Romanini, G. Picó, Protein-flexible chain polymer interactions to explain protein partition in aqueous two-phase systems and the protein-polyelectrolyte complex formation, International Journal of Biological Macromolecules. 41 (2007) 286294. https://doi.org/10.1016/j.ijbiomac.2007.03.006.

[57] E. Tsuchida, Formation of Polyelectrolyte Complexes and Their Structures, Journal of Macromolecular Science, Part A. $\quad 31 \quad$ (1994) $1-15$ https://doi.org/10.1080/10601329409349713.

[58] A. Laschewsky, Recent trends in the synthesis of polyelectrolytes, Current Opinion in Colloid \& Interface Science. $\quad 17 \quad$ (2012) 56-63. https://doi.org/10.1016/j.cocis.2011.08.001.

[59] H.C. Kolb, M.G. Finn, K.B. Sharpless, Click Chemistry: Diverse Chemical Function from a Few Good Reactions, Angew. Chem. Int. Ed. 40 (2001) 2004-2021. https://doi.org/10.1002/1521-

3773(20010601)40:11<2004::aid-anie2004>3.0.co;2-5

[60] X. Wang, F. Schmidt, D. Hanaor, P.H. Kamm, S. Li, A Gurlo, Additive manufacturing of ceramics from preceramic polymers: A versatile stereolithographic approach assisted by thiol-ene click chemistry, Additive Manufacturing. $\quad 27 \quad$ (2019) 80-90. https://doi.org/10.1016/j.addma.2019.02.012.

[61] H.C. Kolb, K.B. Sharpless, The growing impact of click chemistry on drug discovery, Drug Discovery Today. 8 (2003) 1128-1137. https://doi.org/10.1016/s13596446(03)02933-7.

[62] K. Matyjaszewski, A.H.E. Müller, editors. Controlled and living polymerizations.From mechanisms to applications. Weinheim: Wiley-VCH; 2009.

[63] A. Kotzev, A. Laschewsky, R.H. Rakotoaly, Polymerizable Surfactants and Micellar Polymers Bearing Fluorocarbon Hydrophobic Chains Based on Styrene, Macromol. Chem. Phys. 202 (2001) 3257-3267. https://doi.org/10.1002/15213935(20011101)202:17<3257::aid-macp3257>3.0.co;2-p.

[64] G. Decher, Fuzzy Nanoassemblies: Toward Layered Polymeric Multicomposites, Science. 277 (1997) 1232 1237. https://doi.org/10.1126/science.277.5330.1232.

[65] M. Mihai, S. Schwarz, A. Janke, C.A. Ghiorghiţă, E.S Drăgan, Silica microparticles surface coating by layer-bylayer or polyelectrolyte complex adsorption, J Polym Res. 20 (2013). https://doi.org/10.1007/s10965-013-0089-5.

[66] G.B. Sukhorukov, E. Donath, H. Lichtenfeld, E. Knippel, M. Knippel, A. Budde, H. Möhwald, Layer-by-layer selfassembly of polyelectrolytes on colloidal particles, Colloids and Surfaces A: Physicochemical and Engineering Aspects. 137 (1998) 253-266. https://doi.org/10.1016/s0927-7757(98)00213-1. 
[67] A. Pérez-Anes, M. Gargouri, W. Laure, H. Van Den Berghe, E. Courcot, J. Sobocinski, N. Tabary, F. Chai, J.F. Blach, A. Addad, P. Woisel, D. Douroumis, B. Martel, N. Blanchemain, J. Lyskawa, Bioinspired Titanium Drug Eluting Platforms Based on a Poly- $\beta$-cyclodextrinChitosan Layer-by-Layer Self-Assembly Targeting Infections, ACS Appl. Mater. Interfaces. 7 (2015) 1288212893. https://doi.org/10.1021/acsami.5b02402.

[68] J.C. Antunes, C.L. Pereira, M. Molinos, F. Ferreira-daSilva, M. Dessì, A. Gloria, L. Ambrosio, R.M. Gonçalves, M.A. Barbosa, Layer-by-Layer Self-Assembly of Chitosan and Poly $(\gamma$-glutamic acid) into Polyelectrolyte Complexes, Biomacromolecules. $12 \quad$ (2011) 4183-4195. https://doi.org/10.1021/bm2008235.

[69] R. de Vries, F. Weinbreck, C.G. de Kruif, Theory of polyelectrolyte adsorption on heterogeneously charged surfaces applied to soluble protein-polyelectrolyte complexes, The Journal of Chemical Physics. 118 (2003) 4649-4659. https://doi.org/10.1063/1.1543981.

[70] T. Vasconcelos, B. Sarmento, P. Costa, Solid dispersions as strategy to improve oral bioavailability of poor watersoluble drugs, Drug Discovery Today. 12 (2007) 1068 1075. https://doi.org/10.1016/j.drudis.2007.09.005.

[71] C. Kindermann, K. Matthée, F. Sievert, J. Breitkreutz, Electrolyte-Stimulated Biphasic Dissolution Profile and Stability Enhancement for Tablets Containing DrugPolyelectrolyte Complexes, Pharm Res. 29 (2012) 2710 2721. https://doi.org/10.1007/s11095-011-0656-6.

[72] S. Janssens, G. Van den Mooter, Review: physical chemistry of solid dispersions, Journal of Pharmacy and Pharmacology. $61 \quad$ (2009) 1571-1586. https://doi.org/10.1211/jpp.61.12.0001

[73] V.A. Kabanov, Polyelectrolyte complexes in solution and in bulk, Russ. Chem. Rev. 74 (2005) 3-20. https://doi.org/10.1070/rc2005v074n01abeh001165.

[74] A. Hugerth, N. Caram-Lelham, L.-O. Sundelöf, The effect of charge density and conformation on the polyelectrolyte complex formation between carrageenan and chitosan, Carbohydrate Polymers. 34 (1997) 149-156. https://doi.org/10.1016/s0144-8617(97)00088-x.

[75] H. Dautzenberg, W. Jaeger, Effect of charge density on the formation and salt stability of polyelectrolyte complexes, Macromol. Chem. Phys. 203 (2002) 2095 2102. https://doi.org/10.1002/15213935(200210)203:14<2095::aid-macp2095>3.0.co;2-9.

[76] O. Okay, S. Durmaz, Charge density dependence of elastic modulus of strong polyelectrolyte hydrogels, Polymer. 43 (2002) 1215-1221. https://doi.org/10.1016/s00323861(01)00723-6.

[77] Z. Sui, D. Salloum, J.B. Schlenoff, Effect of Molecular Weight on the Construction of Polyelectrolyte Multilayers: Stripping versus Sticking, Langmuir. 19 (2003) 2491-2495. https://doi.org/10.1021/la026531d.

[78] C.L. de Vasconcelos, P.M. Bezerril, D.E.S. dos Santos, T.N.C. Dantas, M.R. Pereira, J.L.C. Fonseca, Effect of Molecular Weight and Ionic Strength on the Formation of Polyelectrolyte Complexes Based on Poly(methacrylic acid) and Chitosan, Biomacromolecules. 7 (2006) 12451252. https://doi.org/10.1021/bm050963w.

[79] A. Shovsky, I. Varga, R. Makuška, P.M. Claesson, Formation and Stability of Water-Soluble, Molecular Polyelectrolyte Complexes: Effects of Charge Density, Mixing Ratio, and Polyelectrolyte Concentration, Langmuir. $\quad 25 \quad$ (2009) 6113-6121. https://doi.org/10.1021/la804189w.

[80] E. Yancheva, D. Paneva, V. Maximova, L. Mespouille, P. Dubois, N. Manolova, I. Rashkov, Polyelectrolyte
Complexes between (Cross-linked)NCarboxyethylchitosan and (Quaternized) Poly[2(dimethylamino)ethyl methacrylate]: Preparation, Characterization, and Antibacterial Properties, Biomacromolecules. 8 (2007) 976-984. https://doi.org/10.1021/bm061029j.

[81] I.Yu. Sakharov, A.Ch. Vorobiev, J.J.C. Leon, Synthesis of polyelectrolyte complexes of polyaniline and sulfonated polystyrene by palm tree peroxidase, Enzyme and Microbial Technology. 33 (2003) 661-667. https://doi.org/10.1016/s0141-0229(03)00188-1.

[82] G.-Q. Huang, L.-Y. Cheng, J.-X. Xiao, X.-N. Han, Preparation and characterization of O-carboxymethyl chitosan-sodium alginate polyelectrolyte complexes, Colloid Polym Sci. 293 (2014) 401-407. https://doi.org/10.1007/s00396-014-3432-4.

[83] T. Delair, Colloidal polyelectrolyte complexes of chitosan and dextran sulfate towards versatile nanocarriers of bioactive molecules, European Journal of Pharmaceutics and Biopharmaceutics. 78 (2011) 10-18 https://doi.org/10.1016/j.ejpb.2010.12.001.

[84] S. Dragan, M. Cristea, Influence of low-molecular-weight salts on the formation of polyelectrolyte complexes based on polycations with quaternary ammonium salt groups in the main chain and poly(sodium acrylate), European Polymer Journal. 37 (2001) 1571-1575 https://doi.org/10.1016/s0014-3057(01)00025-8.

[85] C. Ankerfors, S. Ondaral, L. Wågberg, L. Ödberg, Using jet mixing to prepare polyelectrolyte complexes: Complex properties and their interaction with silicon oxide surfaces, Journal of Colloid and Interface Science. 351 (2010) 8895. https://doi.org/10.1016/j.jcis.2010.07.027.

[86] M. Mende, H.-M. Buchhammer, S. Schwarz, G. Petzold, W. Jaeger, The stability of polyelectrolyte complex systems of poly(diallydimethyl-ammonium chloride) with different polyanions, Macromol. Symp. 211 (2004) 121134. https://doi.org/10.1002/masy.200450709.

[87] I. Insua, A. Wilkinson, F. Fernandez-Trillo, Polyion complex (PIC) particles: Preparation and biomedical applications, European Polymer Journal. 81 (2016) 198215. https://doi.org/10.1016/j.eurpolymj.2016.06.003.

[88] R. Gernandt, L. Wågberg, L. Gärdlund, H. Dautzenberg, Polyelectrolyte complexes for surface modification of wood fibres, Colloids and Surfaces A: Physicochemical and Engineering Aspects. 213 (2003) 15-25 https://doi.org/10.1016/s0927-7757(02)00335-7.

[89] H. Dautzenberg, Polyelectrolyte Complex Formation in Highly Aggregating Systems. 1. Effect of Salt: Polyelectrolyte Complex Formation in the Presence of $\mathrm{NaCl}$, Macromolecules. 30 (1997) 7810-7815. https://doi.org/10.1021/ma970803f.

[90] B. Manisha, V. Devendra, Advanced structured materials. In advances in biomaterials for biomedical applications ( Tripathi, A.; Melo, J. S.; eds) 2017, p. 66, Springer.

[91] J. Berger, M. Reist, J.M. Mayer, O. Felt, R. Gurny, Structure and interactions in chitosan hydrogels formed by complexation or aggregation for biomedical applications, European Journal of Pharmaceutics and Biopharmaceutics. $\quad 57 \quad$ (2004) $35-52$ https://doi.org/10.1016/s0939-6411(03)00160-7.

[92] V.A. Kabanov, A.B. Zezin, A new class of complex water-soluble polyelectrolytes, Makromol. Chem. 6 (1984)

https://doi.org/10.1002/macp.1984.020061984120.

[93] M. Siyawamwaya, Y.E. Choonara, D. Bijukumar, P. Kumar, L.C. Du Toit, V. Pillay, A Review: Overview of Novel Polyelectrolyte Complexes as Prospective Drug 
Bioavailability Enhancers, International Journal of Polymeric Materials and Polymeric Biomaterials. 64 (2015) 955-968. https://doi.org/10.1080/00914037.2015.1038816.

[94] S. L. Patwekar, A. P. Potulwar, S. R. Pedewad, M. S. Gaikwad, S. A. Khan, A. B. Suryawanshi, Review on polyelectrolyte complex as novel approach for drug delivery system. IJPPR. Human, 2016, 5, 97-109.

[95] A.D. Kulkarni, Y.H. Vanjari, K.H. Sancheti, H.M. Patel, V.S. Belgamwar, S.J. Surana, C.V. Pardeshi, Polyelectrolyte complexes: mechanisms, critical experimental aspects, and applications, Artificial Cells, Nanomedicine, and Biotechnology. 44 (2016) 1615-1625. https://doi.org/10.3109/21691401.2015.1129624.

[96] H. Cölfen, S.E. Harding, K.M. Vårum, D.J. Winzor, A study by analytical ultracentrifugation on the interaction between lysozyme and extensively deacetylated chitin (chitosan), Carbohydrate Polymers. 30 (1996) 45-53. https://doi.org/10.1016/s0144-8617(96)00045-8

[97] J.C. Salamone, S. Poulin, A.C. Watterson, A.P. Olson, Ordered polyelectrolyte complex formation from amorphous polyions, Polymer. 20 (1979) 611-614. https://doi.org/10.1016/0032-3861(79)90175-7.

[98] W. Arg elles-Monal, M. G rrciga, C. Peniche-Covas, Study of the stoichiometric polyelectrolyte complex between chitosan and carboxymethyl cellulose, Polymer Bulletin. 23 (1990) 307-313. https://doi.org/10.1007/bf01032446.

[99] S. Dumitriu, Inclusion and release of proteins from polysaccharide-based polyion complexes, Advanced Drug Delivery Reviews. $31 \quad$ (1998) 223-246. https://doi.org/10.1016/s0169-409x(97)00120-8.Top of Form Bottom of Form

[100] M. Antonietti, J. Conrad, A. Thuenemann, Polyelectrolyte-Surfactant Complexes: A New Type of Solid, Mesomorphous Material, Macromolecules. 27 (1994) 6007-6011. https://doi.org/10.1021/ma00099a011.

[101] A. Bhattarai, Micellization behavior of cetyltrimethylammonium bromide in the absence and presence of sodium polystyrene sulfonate in water and methanol-water mixture: A conductivity approach, Journal of Molecular Liquids. $292 \quad$ (2019) 111352. https://doi.org/10.1016/j.molliq.2019.111352

[102] A. Bhattarai, Studies of aggregation properties of surfactant with and without polyelectrolyte in water and binary mixture of methanol-water from the surface tension measurements, Journal of Molecular Liquids. 312 (2020) 113438. https://doi.org/10.1016/j.molliq.2020.113438.

[103] A.S. Michaels, G.L. Falkenstein, N.S. Schneider, Dielectric Properties of Polyanion-Polycation Complexes, J. Phys. Chem. 69 (1965) 1456-1465. https://doi.org/10.1021/j100889a004.

[104] A.S. Michaels, L. Mir, N.S. Schneider, A Conductometric Study of Polycation-Polyanion Reactions in Dilute Aqueous Solution, J. Phys. Chem. 69 (1965) 1447-1455. https://doi.org/10.1021/j100889a003.

[105] H. J. Bixler, A. S. Michaels: Polyelectrolyte complexes. In: Encyclopedia of polymer science and technology. Vol. 10, p. 765. New York; John Wiley and Sons.

[106] V.F. Smolen, D.E. Hagman, A water membrane hypothesis: Behavior of hydrated polycation-polyanion salt complexed membranes as apparent lipoidal barriers to solute transport, Journal of Colloid and Interface Science. 42 (1973) 70-78. https://doi.org/10.1016/00219797(73)90008-8.

[107] R.I. Kalyuzhnaya, A.L. Volynskii, A.R. Rudman, N.A. Vengerova, Ye.F. Razvodovskii, B.S. El'tsefon, A.B.
Zezin, Investigation of the mechanical properties of membranes of polyelectrolyte complexes based on weak polyelectrolytes, Polymer Science U.S.S.R. 18 (1976) 83 90. https://doi.org/10.1016/0032-3950(76)90058-7.

[108] Y. Kurokawa, N. Shirakawa, M. Terada, N. Yui, Formation of polyelectrolyte complex and its adsorption properties, J. Appl. Polym. Sci. 25 (1980) 1645-1653 https://doi.org/10.1002/app.1980.070250812.

[109] R.N. Kadam, R.S. Shendge, V.V. Pande, A review of nanotechnology with an emphasis on Nanoplex, Braz. J. Pharm. Sci. $51 \quad$ (2015) 255-263. https://doi.org/10.1590/s1984-82502015000200002.

[110] X.-Z. Zhang, F.-J. Tian, Y.-M. Hou, Z.-H. Ou, Preparation and in vitro in vivo characterization of polyelectrolyte alginate-chitosan complex based microspheres loaded with verapamil hydrochloride for improved oral drug delivery, J Incl Phenom Macrocycl Chem. 81 (2015) 429440. https://doi.org/10.1007/s10847-014-0471-x.

[111] S.-H. Hu, C.-H. Tsai, C.-F. Liao, D.-M. Liu, S.-Y. Chen, Controlled Rupture of Magnetic Polyelectrolyte Microcapsules for Drug Delivery, Langmuir. 24 (2008) 11811-11818. https://doi.org/10.1021/la801138e.

[112] C. Wang, C. He, Z. Tong, X. Liu, B. Ren, F. Zeng, Combination of adsorption by porous $\mathrm{CaCO} 3$ microparticles and encapsulation by polyelectrolyte multilayer films for sustained drug delivery, International Journal of Pharmaceutics. 308 (2006) 160-167. https://doi.org/10.1016/j.ijpharm.2005.11.004.

[113] F. Amaduzzi, F. Bomboi, A. Bonincontro, F. Bordi, S Casciardi, L. Chronopoulou, M. Diociaiuti, F. Mura, C. Palocci, S. Sennato, Chitosan-DNA complexes: Charge inversion and DNA condensation, Colloids and Surfaces $\begin{array}{llll}\text { B: } & \text { Biointerfaces. } & 114 & \text { (2014) }\end{array}$ https://doi.org/10.1016/j.colsurfb.2013.09.029.

[114] W.-P. Cheng, C. Thompson S.M. Ryan, T. Aguirre, L. Tetley, D.J. Brayden, In vitro and in vivo characterisation of a novel peptide delivery system: Amphiphilic polyelectrolyte-salmon calcitonin nanocomplexes, Journal of Controlled Release. 147 (2010) 289-297. https://doi.org/10.1016/j.jconrel.2010.07.128.

[115] M. Huang, Z.L. Huang, M. Bilgen, C. Berkland, Magnetic resonance imaging of contrast-enhanced polyelectrolyte complexes, Nanomedicine: Nanotechnology, Biology and Medicine. 4 (2008) 30-40. https://doi.org/10.1016/j.nano.2007.10.085.

[116] J.F. Grutsch, Wastewater treatment: the electrical connection, Environ. Sci. Technol. 12 (1978) 1022-1027. https://doi.org/10.1021/es60145a017.

[117] H. Ohno, K. Abe, E. Tsuchida, Makromol. Chem. 182 (1981) $1253-1262$ https://doi.org/10.1002/macp.1981.021820424.

[118] H. Ohno, A. Nii, K. Abe, E. Tsuchida, Makromol. Chem. 182 (1981) 1407-1414 https://doi.org/10.1002/macp.1981.021820513.

[119] E. Tsuchida, K. Abe, Interactions between macromolecules in solution and intermacromolecular complexes, in: Interactions Between Macromolecules in Solution and Intermacromolecular Complexes, SpringerVerlag, $\quad$ n.d.: $\quad$ pp. $1-119$. https://doi.org/10.1007/bfb0017549. 